\title{
Transmission of transport vibrations from the ground to the building - case study
}

\author{
Alicja Kowalska-Koczwara ${ }^{1, *}$ and Filip Pachla ${ }^{1}$ \\ ${ }^{1}$ Cracow University of Technology, Institute of Structural Mechanics, Warszawska 24 St., \\ 31-155 Kraków, Poland
}

\begin{abstract}
Transport vibrations are transmitted from the ground the foundations and building walls to the building and received by its construction and by people in the buildings. During the vibration of buildings, inertia forces generate an additional (apart from the static one) loading of the structure. In the diagnosis and design of buildings, these forces are taken into account by analyzing the requirements for stiffness and strength of the building structure. Exceedance of these requirements may lead to accelerated wear and even structural damages of the building. In this paper a simple relationship between ground and building vibration was made. The building chosen for analysis is light-weight wooden building located close to Cracow near Zakopianka road. What is worth noting that building is so called passive building. The excitation which was simulated on the dynamical polygon was car (bus) and truck lorry passages. The sensors were accelerations in three orthogonal directions, one sensor was placed about $2.5 \mathrm{~m}$ far from the building and the second on the foundation wall. The different types of excitation were compared and the conclusion from the analysis was made.
\end{abstract}

\section{Introduction}

Transport vibrations are transmitted from the ground through the foundations and building walls to the building and received by its construction and by people in the buildings. During the vibration of buildings, inertia forces generate an additional (apart from the static one) loading of the structure. In the diagnosis and design of buildings, these forces are taken into account by analyzing the requirements for stiffness and strength of the building structure. Exceedance of these requirements may lead to accelerated wear and even structural damages of the building. Often the engineers have problem of choosing the right kinematic excitation - from the ground or from the foundation. For existing building both measurements can be made. However when the building is being design there isn't such opportunity. In such cases the numerical studies are made often $[1,6]$. The problem of the vibration propagation through the ground can be found in literature [2, 4, 7] as well as the impact on the buildings [8]. The paper presents the results of transmission of vibrations

*Corresponding author: akowalska@pk.edu.pl 
from the ground to the building. Presented results may in the future be used to assess the effects of vibrations on the buildings as well as on the people in the buildings.

\section{Field tests}

Measurements were carried out on the building located close to Cracow near Zakopianka road. The building chosen for analysis is light-weight wooden building. What is worth noting that building is so called passive building. The excitation which was simulated on the dynamical polygon was car (bus) and truck lorry passages. The sensors were accelerometers in three orthogonal directions, one sensor was placed about $2.5 \mathrm{~m}$ far from the building and the second on the reinforced foundation slab. The thickness of the foundation slab is $35 \mathrm{~cm}$. The foundation depth is $-45 \mathrm{~cm}$ below ground level. The slab is founded on the compacted sand ballast. The thickness of the sand ballast is $50 \mathrm{~cm}$. Near the building soils are cohesive - clay dominates. Accelerations of ground vibrations were measured using PCB 393B12 accelerometers in three orthogonal directions on the foundation and on the ground in front of the building. Fig 1 presents the situation of in situ tests while Fig. 2 shows an example of a measuring point on the ground. The dimensions of the analysed building are presented on Fig. 1. The analyzed building is presented on Fig. 3.

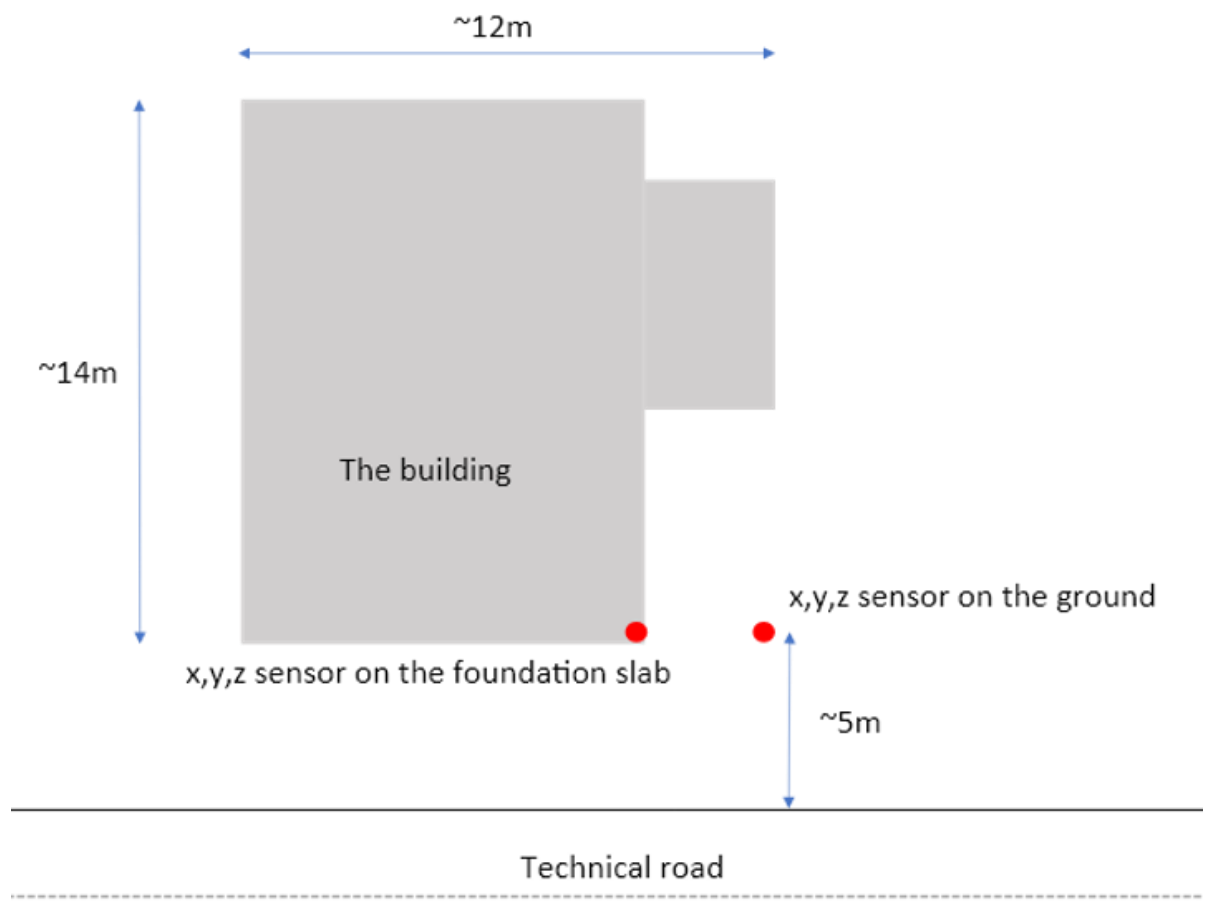

Fig. 1. Localization of the building. 


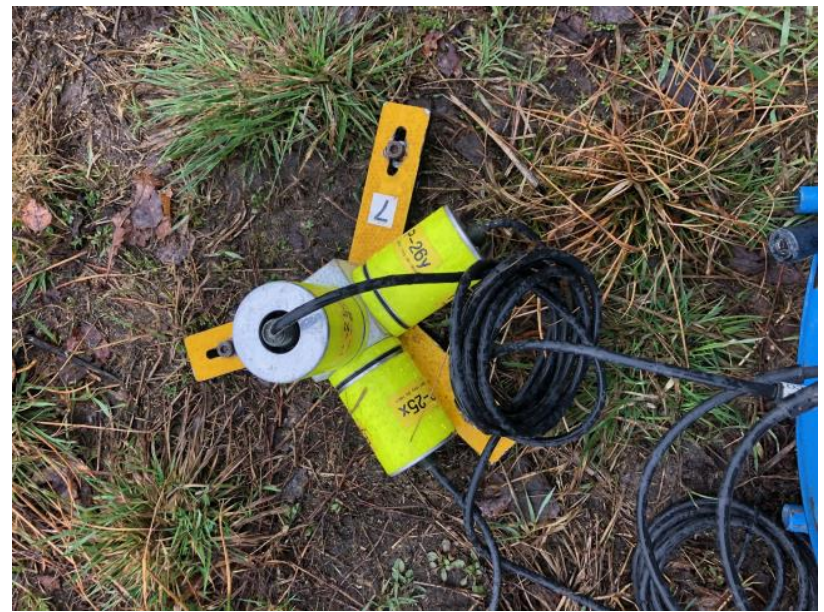

Fig. 2. Acceleration sensors mounted on the ground close to the building.

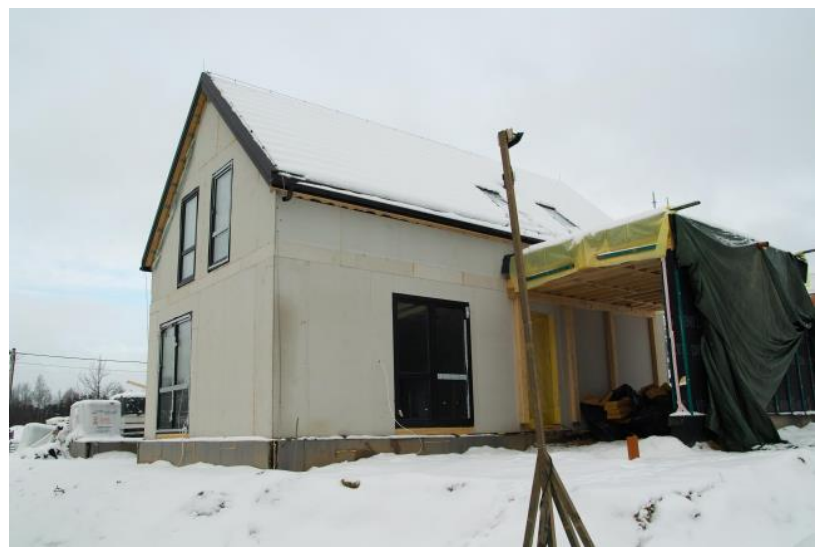

Fig. 3. The analyzed building.

\section{Measurements results and analysis}

Fig. 4 shows the results of vibration measurements in the $x, y, z$ directions on the building foundation after passage of the bus. The values of vibration accelerations do not exceed 11 $\mathrm{cm} / \mathrm{s}^{2}$. Fig. 5, on the other hand, shows the results of acceleration of soil vibrations in front of the building also in three orthogonal directions from the passage of the same bus. From the graph it can be seen that the maximum values of accelerations of soil vibrations are larger. The reduction of the maximum vertical values of acceleration is more than three times. The vertical accelerations of vibrations are most important while analyzing the influence of vibrations on humans in the building. The characteristic mechanism of transferring the vibrations was observed for all analyzed excitations. In the case of $x$ direction (perpendicular to the road) the reduction of peak acceleration is approximately $50 \%$. The reduction of the peak acceleration in the direction y (parallel to the road) is approximately $70 \%$. Horizontal accelerations are most important while analyzing the influence on structural elements. The reduction of vertical peak acceleration is also about $70 \%$. 

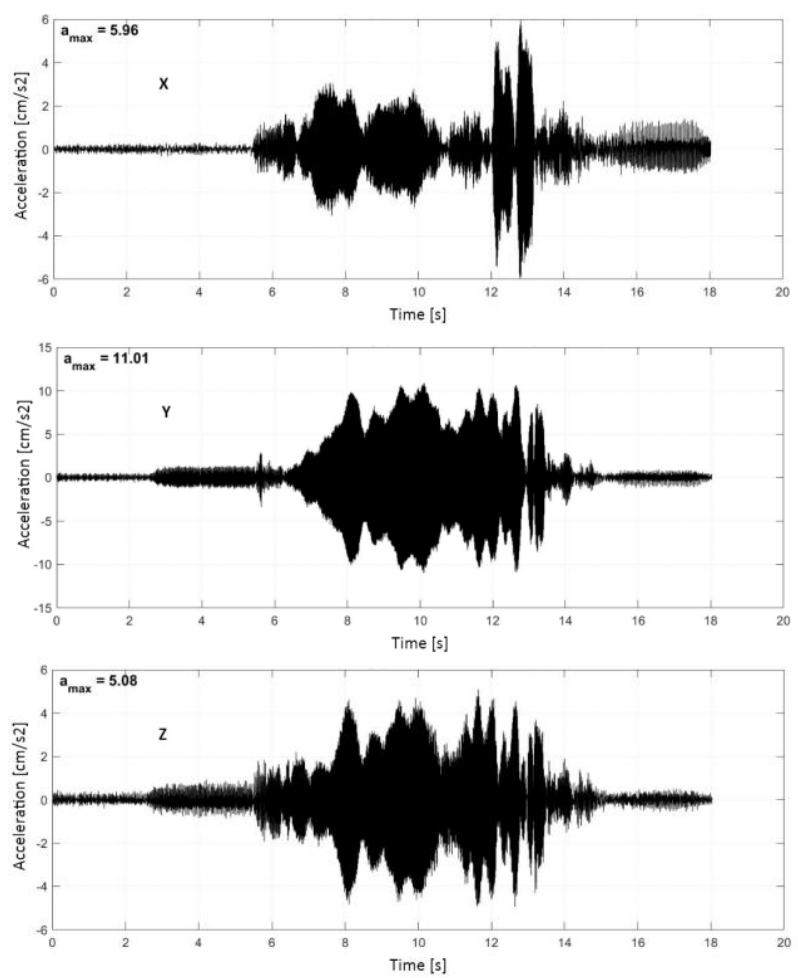

Fig. 4. Vibration records of acceleration on the foundation slab.
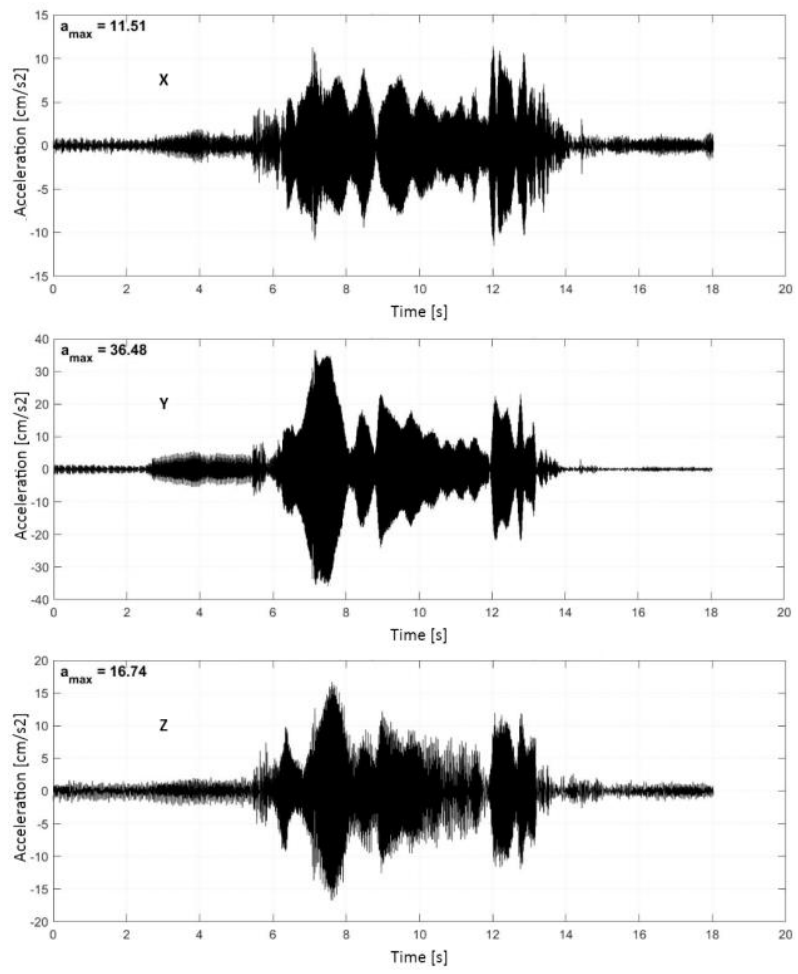

Fig. 5. Vibration records of acceleration on the ground. 


\section{Conclusion}

The research results present characteristic mechanism of vibration propagation from the ground to foundation. The same conclusion can be found in [7], were the influence of the railway vibrations was analyzed. For other induced vibrations, a similar phenomenon can be observed. In the case of mining tremors, high frequencies are filtered [3, 5]. The reduction of the peak vibration accelerations by several times can be observed. The significant reduction was observed for the vertical direction of vibrations. The direction is most important while analyzing the influence on humans in the buildings. Design analysis uses kinematic excitation (measured acceleration) registered on the ground [4, 7]. Lack of proper reduction of this acceleration may lead to oversizing of the structure. In the future, it is necessary to develop transition factors between measurements on the ground and kinematic excitation on boundary conditions of the model. The presented test results can be useful when analyzing vibrations on buildings and humans in the buildings.

\section{References}

1. D. P. Connolly, G. Kouroussis, P. K. Woodward, P. A. Costa, O. Verlinden, and M. C. Forde, Soil Dyn. Earthq. Eng. 67, 102 (2014)

2. A. Kowalska-Koczwara, F. Pachla, P. Stecz, K. Stypuła, T. Tatara, J. Lejk, and M. Sokołowski, Shock Vib. 2018, 8475684 (2018)

3. K. Kuzniar, K. Stec, and T. Tatara, Vibroengineering Procedia VP 35 (2019)

4. K. A. Kuo, G. Lombaert, and G. Degrande, Procedia Eng. 199, 2372 (2017)

5. E. Maciag, K. Kuzniar, and T. Tatara, Earthq. Spectra 32, 1769 (2016)

6. F. Pachla, Vibroengineering \{PROCEDIA\} 19, 147 (2018)

7. F. Pachla, Vibroengineering \{PROCEDIA\} 27, 93 (2019)

8. F. Pachla, B. R. Pawlik, K. Stypuła, and T. Tatara, Vibroengineering \{PROCEDIA\} 13, 188 (2017)

9. W. Zhai, K. Wei, X. Song, and M. Shao, Soil Dyn. Earthq. Eng. 72, 24 (2015) 